\title{
Design Studios for K-12 Computing Education
}

\author{
Megan Venn-Wycherley \\ Open Lab, Newcastle University \\ Newcastle-upon-Tyne, UK \\ m.venn-wycherley@newcastle.ac.uk
}

\author{
Christine Bennett \\ Churchill Community College \\ Newcastle-upon-Tyne, UK \\ chrisbennett0801@gmail.com
}

\author{
Ahmed Kharrufa \\ Open Lab, Newcastle University \\ Newcastle-upon-Tyne, UK \\ ahmed.kharrufa@newcastle.ac.uk
}

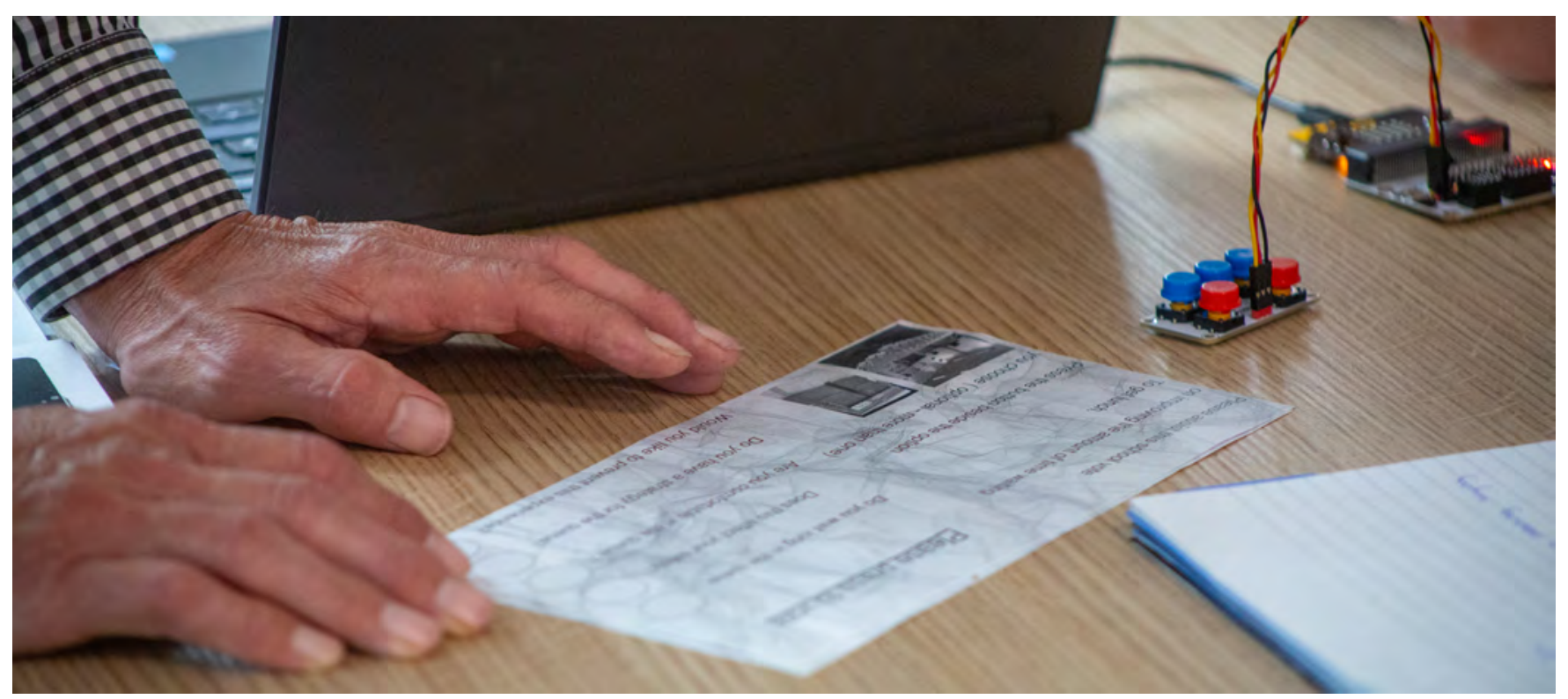

Figure 1: A pupil demonstrates their poster voting project on school lunch queue management to a researcher

\begin{abstract}
Following the decline of pupil engagement in compulsory computing education (K-12) in the UK, advocates have called for further research into computing-specific pedagogies. Aiming for an improvement in pupil engagement, the subsequent report explores the viability of the applied Design Studio approach in K-12 computing education. We report on two case studies involving two 12-week curricula co-developed and delivered between researchers and teachers for four Year 8 classes in a secondary school in England. Common to both case studies were the design brief, desk crit, design review, presentation and portfolio elements proposed by Koutsabasis et al, with the key difference being a change in scope and structure of the challenge presented to pupils. Our findings demonstrate the need for a well-structured, personalizable and challenge-driven Design Studio approach, which showed evidence of improved pupil resilience and confidence, while engaging reluctant pupils. We conclude with a proposed model for applying Design Studios in K-12 computing education, to support educators aiming to adopt project-driven computing pedagogy in the classroom.
\end{abstract}

\section{CCS CONCEPTS}

- Social and professional topics $\rightarrow$ Computer science education; K-12 education.

\section{KEYWORDS}

computing education, pedagogy, secondary school, K-12 education, design studio

\section{INTRODUCTION}

In the past decade, computing education in schools has progressed from the utilization of computers to the design and criticality of computing technologies [2, 22]. This reformed approach to K-12 computing education on an international scale $[8,9]$ has aimed to provide young people with basic skills for a modern, digital society. The current approach to K-12 computing in the UK is "patchy and fragile", with poor support for teachers and limited access to resources [18]. Reports outline further concern that the number of young people choosing to study computing in the UK is in decline, attributed to pupils having difficulty in understanding programming concepts, poor resilience in the face of challenges, and a lack of interest in the topic $[18,19]$. This current approach has been deemed a risk to "the education of future generations" [18], with potential to exacerbate existing social inequalities and contribute toward the development of a "digital underclass" [5].

Advocates for computing education have called for the development of computing-specific pedagogies, with a focus on programming and pupil engagement [21]. A key recommendation includes an increased focus on the application of computing concepts in 
the real world [18]. Examining the pedagogical field of computing at Higher Education (HE), Human-Computer Interaction (HCI) is an applied computing discipline focusing on the interaction of people and technology in real world settings. The HCI Design Studio approach, proposed by Reimer and Douglas for HE computing students [17], reports an improvement in active learning and engagement $[6,12]$. Despite this, there is a limited exploration of Design Studios for K-12 computing (e.g. a keyword search on the ACM Digital Library for "design studios" and "K-12 education" returned no relevant results as to the date of this paper).

This paper reports on the application of the Design Studio approach in K-12 computing education. Across a six-month period, a team of three computing teachers from one school, and computing education researchers from an HCI lab worked to co-develop a 12 week Design Studio computing curriculum for Year 8 pupils (12-13 years old), which was trialed with four classes across two terms. Following a design-based research approach paired with a case study methodology, we seek to contribute towards an understanding of 1) the Design Studio approach in K-12 computing and 2) the impact of the Design Studio approach on pupil engagement in computing. We then reflect upon these findings to 3) provide a model for adopting the Design Studio approach in K-12 classrooms.

\section{BACKGROUND}

\subsection{The Design Studio Approach}

Further to Reimer and Douglas' work on Design Studios, others have reported positive learning outcomes when adopting a Design Studio approach for HE computing education [10, 12, 17]. However, a limitation of the Design Studio approach is the lack of lecture elements, as students are expected to attend background courses to supplement their understanding $[10,12]$, which is not standard practice at K-12. Koutsabasis et al. attempted to address the limitations of the approach by blending Design Studio activities, core HCI concepts and problem-based learning to support undergraduate students in their HCI studies [12]. The aim of this approach was to achieve balance between the theoretical and practical elements inherent to $\mathrm{HCI}$, and as such, highlighted two main approaches that an educator might take in applying a Design Studio model These were: 1) a domain-driven approach: presenting students with a general thematic domain within which to develop their projects, to which they must respond with a concrete proposal, and 2) a project-driven approach: involving a structured design brief with specific requirements and constraints to structure the project. These two approaches guide the design of the research.

\subsection{Computing Education at K-12}

Teacher observation noted that pupils could begin secondary school with a good grounding and keen interest in computer science, but would rapidly lose their enthusiasm if there wasn't effective teaching practice or supportive infrastructure [16]. Previous research suggests that pupils learning is best motivated when it is "connected with things [they] care about" [11] and that a learner is best engaged when a project is situated within their interests. Current findings suggest that pupils cite a "lack of interest" in the topic, and prioritize "other subjects ahead of computing" [18], suggesting that computing lacks applicability to their own interests. Additionally, another common challenge experienced by K-12 computing pupils, is that of resilience. Teachers perceive that pupils are not prepared to independently solve programming problems and give up quickly in the face of challenges, attributed to lack of understanding and confidence [19].

\subsection{Computing Education at Higher Education}

In HE, computing education has moved away from focusing on syntax to the solution of real-world problems through transferable concepts and constructs. While it is noted that the aim of this approach is not to create industry-ready individuals, it helps students to understand the use of programming in a wider context and provides them with an internal framework for understanding new languages, tools and methods that they might encounter in the future [3]. Through the multidisciplinary nature of HCI, students can be introduced to transferable, applied concepts around design, ideation and evaluation $[4,15]$. However, it is important note that HE educators have flexibility in the development of their curricula, where educators in compulsory education are likely to adhere to national standards or the requirements of awarding bodies.

\section{METHODOLOGY}

In July 2018, a non-selective, mixed-gender secondary school contacted our HCI research group about the opportunity to collaborate on the development of a computing curriculum for Year 8 pupils (1213 years old). The school was situated in an area of socio-economic deprivation, with $42.1 \%$ of the pupil population identified as disadvantaged due to familial upheaval or financial difficulty. The school identified difficulties in engaging pupils in the transition from block to text-based programming, and were interested in developing a challenge-based curriculum employing the BBC micro:bit (small, programmable physical computing devices). The HCI lab were already involved in the delivery of a Design Studio-based HCI course at HE, and we chose this opportunity to explore the viability of Design Studios for K-12 computing. Teachers and researchers collaboratively developed a model, with researchers positioned as external subject experts who commissioned a classroom-based challenge for pupils. The school identified four classes to participate in the study, determined by the timetable and academic ability. This resulted in two main case studies, each comprising of two concurrent Year 8 classes.

\subsection{Approach}

Due to the limited understanding of the application of Design Studios for K-12 computing education, the study adopted an instrumental, exploratory case study approach [13]. While the participants and findings are particular to their context, the instrumental case study approach hopes to generate broader, novel insights for the application of Design Studios in wider K-12 computing classes. The main units of analysis in the two cases studies were the class, which involved the teachers, pupils and lead researcher. The educational context of the planned case studies also led to the use of a design-based research methodology [1], in an iterative, collaborative partnership focusing on the combined expertise of participating researchers and teachers, culminating in a series of recommendations for Design Studios for K-12 computing education. 
Using Koutsabasis et al's Design Studio framework as a theoretical basis, two main case studies were designed to determine the viability of Design Studios for K-12 computing education. The first case study would be a domain-level Design Studio, where pupils were tasked with using their computing skills to create an artefact under the theme of assistive technology. The second case study would be a structured project-level Design Studio, where pupils would create digital voting posters. In the collaboration, challenge areas were chosen for the expertise of the HCI lab and lead researcher, and pedagogical and curricular expertise were the purview of involved teaching staff.

\subsection{Data Collection}

The research follows a qualitative approach, inherent to case studies, involving multiple data sources to corroborate evidence from participating researchers, teachers and pupils. The lead researcher kept an observational diary to compare against teacher observational entries, which included perspective of the lessons, as well as identified opportunities and challenges. These comparisons acted as the basis of the reflective semi-structured interviews between teachers and the lead researcher carried out at the end of the project. Pupils were involved in evaluative focus groups lasting 50 minutes. These findings were supplemented by pupils' verbal observations of participation in the project. Utilizing indirect indicators such as behavior data recorded by the school, in combination with teacher and researcher recorded observations, allowed for an understanding of changes in pupil engagement.

\subsection{Data Analysis and Interpretation}

Data was analyzed through inductive thematic analysis, with emergent coding noting areas of importance throughout the data sources. Due to the long-term nature of the case studies, the data was coded and presented back to teachers in a "back-talk" approach [7] to ensure findings were evaluated by subject specialists. Furthermore, this paper was co-authored and reviewed by participating teachers, providing context for our findings.

\section{CASE STUDIES}

The following sections outline the planning, execution and reflection of two case studies of Design Studios for K-12 computing, the first exploring a domain-driven approach and the second a projectdriven approach. Both case studies include the recommended elements of: 1) a design brief: to outline a challenge for the pupils, 2) $a$ desk crit: teachers and pupils respond to pupil-generated ideas, 3) $a$ design review: researcher feedback on pupil work, followed by 4) a presentation and 5) a portfolio for pupils to display work to the wider HCI lab [12].

\subsection{Case Study 1 - a domain-driven approach}

Class 1 was comprised of 24 pupils (14 female and 10 male). Their teacher, Teacher1, was a male with five years teaching experience and was acting departmental head of business and computing. He had specialist computing knowledge and training, and often volunteered in new ventures. Class 2 was comprised of 27 pupils (11 female and 16 male), who were taught by Teacher2. He was a male teacher with two years teaching experience, acting as a contracted maternity cover for one year. His original degree was in business studies, but was required to teach computing. Both Class 1 and Class 2 were average ability classes within their year group and had one 50-minute computing lesson per week, spanning 12 teaching weeks from January to April.

4.1.1 Plan. The domain for the pupils was assistive technologies, chosen by Teacher 1 and the researcher, based on a specialization of the HCI lab. In first six weeks, pupils would focus on developing practical and theoretical skills, culminating in a project proposal desk crit with teachers and peers (to ensure sensible responses). The subsequent six weeks were to be open "project time" to respond to the challenge. Pupils would have tutorials to support their programming of the $\mathrm{BBC}$ micro:bit, as well as visits from a small group of $\mathrm{HCI}$ researchers to give expert feedback on their work. At the end of the course, pupils would attend a showcase at the University to demonstrate their project and portfolio materials to the wider HCI lab. The lead researcher would be present for the majority of lessons, and provide specialist feedback for pupils.

4.1.2 Execution. Initially, the project started with good observed levels of pupil engagement. However, poor behavior from a small number of pupils led to class disruption. This, in addition to several fire alarms, meant that lessons became delayed as theoretical elements were often repeated. This began to encroach on the "free project" weeks of the curriculum, leading to further disengagement from pupils and frustration from the teachers and researchers.

This disruptive behavior was experienced in both Class 1 and 2. Teacher 1 and the lead researcher made the decision for the researcher to not attend lessons for one week in attempt to improve behavior. However, increasingly poor behavior finally led to project termination on Week 9 for Class 1 and termination for Class 2 on Week 10. As organized with the school, the classes returned to their original scheme of work for computing, and no final showcase took place.

4.1.3 Findings. Engagement: Through the first six weeks, lessons were frequently interrupted by fire alarms, leading Teacher 1 and Teacher2 to revisit incomplete topics. Due to these interruptions, Teacher2 noted that "It was a weird time, there was no flow to lessons," and this led to an observed increase in pupil disruption and demotivation. Continuous disruption and poor behavior from other pupils culminated in teachers being unable to continue with the Design Studio approach. However, this disruption was not considered out of character for Class 1 or Class 2, with Teacher1 remarking "it doesn't matter what you would have done, they'd have acted the same."

Furthermore, the unclear position of the researcher in the classroom caused pupils' some confusion, as the researcher was wearing a school staff badge. This led to the perception that the researcher was another member of staff, with Teacher2 commenting that pupils perceived the researcher to be "just another boring teacher." Instead, it was suggested that a clear distinction of the researcher as a visitor might improve pupil engagement: "They like having guests in. It makes them feel a bit more special... I think if you wore a visitor's badge it would help - be more of a specialist or a guest, as opposed to just another teacher."

Lessons Learned 
- A need for a flexible scheme of work, to cope with delays or interruptions

- Position experts as visitors to improve engagement.

Framing in everyday realities: Despite the domain brief of assistive technologies being co-developed between researchers and teachers, pupils struggled to understand a project that was outside of their everyday realities and interests. One particularly disengaged girl pointed out that Kim Kardashian would say computing is "a waste of time" which sparked a discussion amongst pupils about why Kim Kardashian might not agree with that statement. When computing was situated within their world of interests, they were more willing to engage. Papert proposed that "The key educational task is to make connections between powerful ideas and passionate interests" [14], and this demonstrates a need for a Design Studio to reflect the passionate interests of the pupils' everyday realities.

\section{Lessons Learned}

- Allow project to be situated in the experience and interests of the pupils

Resilience: Observations from both Teacher1 and Teacher2 noted there was a need to "run around helping 'helpless' students" who found it easier to wait for a teacher, than to try resolve programming problems themselves. Teacher2 noted that pupils had limited "perseverance and that sort of-ability to think outside the box and say "where is the problem?"' Independent activity sessions were provided by the co-creation of supplementary two-page tutorials to scaffold the pupils in the guided discovery of programming concepts. However, pupils struggled to work independently, reporting that they "just didn't get it" and would "get in a strop if it didn't work." Teacher2 suggested that pupil resilience could be improved through a "step-by-step guide" with a clear outline of project expectations and constraints, to be integrated into the development of pupils' portfolios.

\section{Lessons Learned}

- Provide a structured portfolio of for pupils to complete, supporting independent work and problem solving

Domain-driven approach: Both Teacher1 and Teacher2 made comment on the difficulties of supporting all students who encountered difficulties when completing coding tasks. Teacher2 summarized this by saying "you just don't have time to go around everyone", as "it's difficult if you've got 30 kids and one teacher," which was exacerbated by the divergent nature of pupils' assistive technology projects. Each pupil approached the project in their own unique way, with one pupil creating a way for non-verbal people to communicate via emoji, while another created an automatic door system for those with physical impairments, which both had vastly different underlying code bases. Ultimately, the research team and teachers determined that the variety of projects created under a domain-driven Design Studio approach was overly challenging to support in the K-12 computing classroom.

\section{Lessons Learned}

- Focus on a project that has the same underlying base of code, with room for personalization in supplementary features and context of use

\subsection{Case Study 2 - A project-driven approach}

Class 3 was comprised of 21 pupils ( 10 female and 11 male) and Class 4 was comprised of 22 pupils (11 female and 12 male). Teacher3, a female teacher with over 15 years of experience in business and computing, taught both classes. She was contracted by the school to cover maternity for one year. Class 3 and Class 4 were below average ability classes, in comparison to their year group. Therefore, both classes had two timetabled 50-minute computing lesson per week, taught across 12 teaching weeks from April to July, resulting in 24 lessons.

4.2.1 Plan - Responding to Case Study 1. In response to Case Study 1, the subsequent Design Studio approach needed a structured scheme of work for pupil support, an identical code base for teacher delivery, and the potential for content personalization, to allow pupils to create personally meaningful projects. The need for an underlying code structure led to the creation of Digital Voting Posters. Every pupil-created voting system would have the same base code (built upon iteratively each lesson), while the poster was to be based on the improvement of the school environment. The ultimate topic and visual design of the poster would be the decision of the pupils.

The scheme of work was structured to teach pupils the practical elements involved in creating the digital voting system across 20 lessons (10 weeks), with some lessons being "non-critical" to allow for delays or disruptions. The last four lessons would be devoted to pupils finishing and personalizing their posters and voting systems. Class work would be recorded by the students in a portfolio known as the "Researcher's Handbook", to address the lack of guided discovery in Case Study 1.

Design reviews were planned three weeks before project handin, and would be conducted by $2-3$ researchers visiting a class to provide feedback on their projects. This would culminate in a university showcase for pupils to demonstrate their projects and portfolio materials to the wider HCI lab.

To address the misconception that the researcher was "just another teacher", it was agreed that she would only attend sessions where an expert presence was justified (e.g. introducing the challenge, evaluation etc.), and delivery of lessons would be the responsibility of the teacher. Additionally, the lead researcher would no longer wear their school staff badge, and instead wear a visitors badge to be clearly marked as an "outsider".

4.2.2 Execute. Out of the scheme of work, only the critical path lessons were completed - this was much slower than previously anticipated. However, this was not a negative finding, as the flexibility of the scheme of work could allow Teacher3 to extend lesson where pupils had been observed to become more engaged. The tutorials used in Case Study 1 were implemented as extension materials for keen pupils. Finally, pupils attended a showcase at the University to demonstrate their projects to members of the HCI lab and the wider University.

4.2.3 Findings. Engagement of powerful ideas and passionate interests: Overall, observations indicated an improvement in pupil engagement, with behavior data corroborating this by demonstrating a drop from 20 behavior codes issued in the Autumn and Spring terms, to just one in the Summer Design Studio term for Class 3. 
Class 4 showed a similar decline from 39 issued behavior codes in Autumn and Spring terms to only five in the Summer term. This is not to say there was no signs of poor behavior, as Class 4 were poorly behaved prior to the arrival of the visiting researchers in the Design Review. After the researchers had left, pupils immediately asked Teacher3 if they had "pulled it back" with their improved behavior for the rest of the lesson. In response to the importance of external visitors, Teacher3 noted that: "[The pupils] did care. They really did care. But they wouldn't show anybody, because that's not cool”.

Additionally, Teacher3 recounted two personally surprising events which occurred during the project. The first was a group of three female pupils who initially had been reluctant to engage with the project, and computing overall. Towards the end of the project, these pupils were found to be working on the creative elements of their poster systems at lunchtimes and after school. A further group of five students stayed after school to create supplementary showcase materials. Teacher3 noted that "if [the project] had just been code without something they could color, enjoy and make pretty, I don't think they would have been as engaged." The pupils themselves reported that the creation of the poster and showcase materials also improved their understanding of more complex computing concepts, suggesting that creativity can be positioned in a curriculum to engage reluctant pupils in their computing studies.

The structured, yet personalizable nature of the voting systems led to an observed increase in engagement, as it allowed pupils to explore their personal interests. One group of female pupils in Class 3, initially disinterested in computing, created a poster voting system to promote access to the school dance studio by allowing pupils to vote for their preferred day of use, so that the school could provide supervision. In Class 4 , a group created a poster for voting on the reorganization of the lunch queues, as it could often take 20 minutes to purchase food. Some pupils struggled to reach an engaging topic within school improvement, with Teacher3 suggesting a completely open topic to engage students further: "[even if] it was something like 'who do you think will get relegated this season?' [in soccer] and they had five teams that they could choose from... Fust, any multiple choice question would do the same thing." The structure of the Design Studio would allow for such flexibility of scope, while retaining the supportive structure of a logically similar code base - voting systems.

When discussing the role of the researcher in pupil engagement, Teacher3 said "the kids really respected having an expert who came in to help... I think, having you there made a massive difference to how seriously the kids took it." While the pupils reported they would have preferred "even more researchers" in the classroom to assist with their projects.

It is important to acknowledge the extended length of the Case Study (100 minutes/week) and the experience of Teacher3. We argue that the more time allocated led to improved engagement and student ownership of their projects, and more time should be allocated to computing to allow for increased pupil engagement.

\section{Lessons Learned}

- Provide a structured scheme of work that allows for a personalizable approach with a fixed scope, allowing for improved teacher support and pupil engagement
A confidence boost: Initially, some pupils were nervous about attending the showcase, as Teacher 3 highlighted it was possible that some pupils had never even been to the City before (a trip of approximately seven miles). Despite this, in the final focus group, one female pupil reported enjoying being "trusted to go off on their own and work" to prepare for the main exhibition and that it helped to improve their confidence in the work they had produced. This improvement in behavior was corroborated by a surprised Teacher1, who remarked upon the confidence and professional behavior displayed by Class 3 and 4 upon preparing for their showcase event. Pupils also noted that in attending the showcase, they "felt like [their] confidence was boosted by explaining what [they'd] learned", and that they "could actually talk about what computers do" when presenting their work to attending HCI researchers at the showcase. Lessons Learned

- Provide opportunities for pupils to engage and share their computing knowledge with "outsiders"

"I learned to never give up": When asked about the difference in resilience between the classes in Case Study 1 and her classes in Case Study 2, Teacher3 commented that Class 3 and 4 "would give [programming] a shot in a way that the previous group didn't" as her classes were used to not getting things right first time. This was evident during a desk crit, where a group of female pupils created $140+$ versions of their final code, as they wanted experiment and personalize their project in response to feedback. When asked directly about their experiences on the project, pupils reported that the project had "stretched my mind and made me think" and they "learned to never give up" when they encountered programmingrelated problems, so kept iterating in the development of their code and recording their work in their portfolio Researcher's Handbook. This suggests a need for pedagogy focused on the exploratory nature of coding, rather than focusing on a perfect voting system. 


\section{Lessons Learned}

- Allow pupils an opportunity to iterate in the development of their project ideas, for improved resilience

\section{DISCUSSION}

Through the two case studies, we seek to contribute towards the development of the Design Studio as a pedagogical approach for $\mathrm{K}-12$ computing, towards the improvement of pupil engagement, confidence and resilience. In response to the findings above, we present the beginnings of a viable model for the implementation of a Design Studio approach in the classroom, including suggested structure, limitations and future work.

\subsection{The Structure}

Disruptions ranging from fire alarms to pupil behavior are typical in the K-12 classroom, which positions the flexibility of a scheme of work as a matter of central importance. To respond to this issue, we suggest a "critical path" approach to the Design Studio structure, with a minimum set of key lessons to achieve the commissioned challenge topic, and the use of additional, "non-essential" lessons to achieve further conceptual understanding where timetabling allows.

\subsection{The K-12 Design Studio Model}

Following our exploration of the Design Studio approach for K-12 computing, we propose a viable model for educators to adopt this HE HCI pedagogy in the classroom. The following sections are structured using Koutsabasis et al's Design Studio elements [12].

5.2.1 The Design Brief. Addressing the recommendation that pupil engagement is best achieved when "connected with things [they] care about," [11] the design brief must allow pupils to create and personalize computing projects. This helps to address the underlying issues with pupils lacking an interest in the subject, by positioning computing concepts within their everyday realities, interests and experiences. This approach to the design brief, can also help to address the application of computing in the real world.

Furthermore, we observed that the constrained and structured scope of the project-driven approach, with a similar underlying code base, supported pupil engagement yet prevented a divergence in project code that teachers may struggle to support in the classroom. This "open project-driven approach" could engage reluctant pupils, not only through personalization but also through creativity, while retaining a rigid code base. For example, digital voting posters allowed pupils to choose to collect information about a topic of interest or experience, ranging from soccer to dance to environment. Therefore, this suggests that exploring the transmission of topics of interest would be a suitable project for a Design Studio through, for example, the creation of computing-enhanced adverts or banners.

5.2.2 The Desk Crit. The importance of a desk crit is vital when considering the development of resilience of pupils in computing education. As a project critique, peers and teachers can offer opinions and alternatives to early versions of pupil work, allowing pupils to explore and iterate in the development of their projects. Linking back to resilience, this provides pupils with a focus on developing their code in the face of new opinions or information.
5.2.3 The Design Review. External visitors, positioned as subject experts in the design review, helped to engage pupils in computing through provision of critical feedback and support. Attempting to scale a design review, with just researchers may prove difficult due to time constraints. However, there may be potential to leverage wider university resources in the form of undergraduate computing students [20], who could be placed in a "critical friend" role to provide support and feedback for pupils in design reviews. Additionally, these external experts could be other subject-specialist teachers who are "outside" the pupil's learning experience.

5.2.4 The Presentation. In this report, it was observed that students who did not typically engage with computing responded to the creativity afforded by the presentation element of the projectdriven approach, which additionally improved their self-confidence. However, it is important to consider the scalability of attending a university showcase as a finale of a Design Studio. Limited time and resources could negatively impact the viability of a showcase, while transitioning poorly to schools which are geographically distanced from a university. From our findings, it is important that this element of connection between the university and schools is maintained as it provides pupils with the real world application of computing concept. A method for conserving this relationship could be through pupil submission of video/audio demonstrations for an online showcase, to be reviewed and commented upon by external researchers or specialists.

5.2.5 The Portfolio. The portfolio should be separated into two elements: a workbook and a handbook. The workbook will act as a repository for completed exercises and examples, allowing pupils to refer back to their own work when problem-solving in support of the resilience. The handbook will act as a non-critical source of guidance.

\subsection{Limitations and Future Work}

It is important to recognize that the findings of the above case studies are a product of their context and participants. More work must be done to determine the efficacy of the "open project-driven approach" in K-12 computing Design Studios, and how educators might be supported to adopt this pedagogical model.

We plan to achieve this by exploring the model with Year 8 classes in further schools, as we continue to iterate and explore Design Studios for K-12 computing. Currently, there is one secondary school planning to participate in an evaluative study of the model. Furthermore, all developed resources are provided as accessible, Open Educational Resources, such that K-12 computing educators around the world can adopt and adapt the project materials for use in their own classrooms.

\section{CONCLUSION}

Through this report, we have detailed an exploration into the use of Design Studios for K-12 computing education. We contribute an understanding of the implementation of the Design Studio approach in a K-12 context, as well as outline the impact when choosing between a domain and project-driven approach. Reflecting upon these findings, we culminate in a proposed model for adopting the Design Studio approach in K-12 classrooms. 


\section{ACKNOWLEDGMENTS}

We would like to express our sincere thanks to all those who took part in the above research, particularly to the staff and pupils without whom this would not have been possible. This work was funded by EPSRC award EP/L016176/1 (Centre for Doctoral Training in Digital Civics.)

\section{REFERENCES}

[1] Terry Anderson and Julie Shattuck. 2012. Design-Based Research A Decade of Progress in Education Research? Educational Researcher 41, 1 (2012), 16-25. https://doi.org/10.3102/0013189X11428813 arXiv:https://doi.org/10.3102/0013189X11428813

[2] David Barr, John Harrison, and Leslie Conery. 2011. Computational Thinking: A Digital Age Skill for Everyone. Learning \& Leading with Technology 38, 6 (2011), $20-23$.

[3] James H Davenport, Alan Hayes, Rachid Hourizi, and Tom Crick. 2016. Innovative pedagogical practices in the craft of computing. In Proceedings - 2016 Internationa Conference on Learning and Teaching in Computing and Engineering, LaTiCE 2016. IEEE, 115-119. https://doi.org/10.1109/LaTiCE.2016.38

[4] Rahmad Dawood. 2016. Embedding HCI in Computer Science Education: A Preliminary Attempt. In Proceedings of the $2 \mathrm{Nd}$ International Conference in $\mathrm{HC}$ and UX Indonesia 2016 (CHIuXiD '16). ACM, New York, NY, USA, 39-43. https: //doi.org/10.1145/2898459.2898465

[5] Paul DiMaggio and Filiz Garip. 2011. How Network Externalities Can Exacerbate Intergroup Inequality. Amer. f. Sociology 116, 6 (2011), 1887-1933. http://www. jstor.org/stable/10.1086/659653

[6] Michael Docherty, Peter Sutton, Margot Brereton, and Simon Kaplan. 2001. An Innovative Design and Studio-based CS Degree. In SIGCSE '01 Proceedings of the thirty-second SIGCSE technical symposium on Computer Science Education. ACM, Charlotte, 233-237.

[7] Annalisa Frisina. 2006. Back-talk Focus Groups as a Follow-Up Tool in Qualitative Migration Research: The Missing Link? Forum Qualitative Sozialforschung / Forum: Qualitative Social Research 7, 3 (2006). https://doi.org/10.17169/fqs-7.3.138

[8] Judith Gal-Ezer and Chris Stephenson. 2014. A Tale of Two Countries: Successes and Challenges in K-12 Computer Science Education in Israel and the United States. ACM Trans. Comput. Educ. 14, 2, Article 8 (June 2014), 18 pages. https //doi.org/10.1145/2602483

[9] Peter Hubwieser, Michail N. Giannakos, Marc Berges, Torsten Brinda, Ira Diethelm, Johannes Magenheim, Yogendra Pal, Jana Jackova, and Egle Jasute. 2015
A Global Snapshot of Computer Science Education in K-12 Schools. In Proceedings of the 2015 ITiCSE on Working Group Reports (ITICSE-WGR '15). ACM, New York, NY, USA, 65-83. https://doi.org/10.1145/2858796.2858799

[10] Christopher Hundhausenm, Dana Fairbrother, and Marian Petre. 2010. The "prototype walkthrough": a studio-based learning activity for the next generation of HCI education. (2010), 3.

[11] David Kestenbaum. 2005. The challenges of IDC. Commun. ACM 48, 1 (2005), 35. https://doi.org/10.1145/1039539.1039566

[12] Panayiotis Koutsabasis, Spyros Vosinakis, Modestos Stavrakis, and Panagiotis Kyriakoulakos. 2018. Teaching HCI with a studio approach. In Proceedings of the 22nd Pan-Hellenic Conference on Informatics - PCI '18. ACM, New York, NY, USA, 282-287. https://doi.org/10.1145/3291533.3291561

[13] Jonathan Lazar, Jinjuan Heidi Feng, and Harry Hochheiser. 2017. Chapter 7 Case studies. In Research Methods in Human Computer Interaction (Second Edition) (second edi ed.), Jonathan Lazar, Jinjuan Heidi Feng, and Harry Hochheiser (Eds.). Morgan Kaufmann, Boston, 153-185. https://doi.org/10.1016/B978-0-12-8053904.00007-8

[14] Seymour Papert. 1980. Mindstorms: children, computers and powerful ideas (2nd ed.). Basic Books, New York.

[15] Fabio Pittarello, Gualtiero Volpe, and Massimo Zancanaro. 2017. HCI and Education in a Changing World: From School to Public Engagement. In Proceedings of the 12th Biannual Conference on Italian SIGCHI Chapter (CHItaly '17). ACM, New York, NY, USA, Article 31, 2 pages. https://doi.org/10.1145/3125571.3125576

[16] Pye Tait Consulting. 2017. After the reboot: the state of computing education in UK schools: Final Report. (2017), 1-123.

[17] Yolanda Jacobs Reimer and Sarah A. Douglas. 2003. Teaching HCI Design With the Studio Approach. Computer Science Education 13, 3 (2003), 191-205. https: //doi.org/10.1076/csed.13.3.191.14945

[18] Royal Society. 2017. After the reboot : computing education in UK schools SUMMARY. (2017).

[19] Sue Sentance and Andrew Csizmadia. 2017. Computing in the curriculum: Challenges and strategies from a teacher's perspective. Education and Information Technologies 22, 2 (01 Mar 2017), 469-495. https://doi.org/10.1007/s10639-0169482-0

[20] M. Venn-Wycherley and A. Kharrufa. 2019. HOPE for Computing Education: Towards the Infrastructuring of Support for University-School Partnerships. In In Proceedings of the 2019 CHI Conference on Human Factors in Computing Systems. ACM, New York, NY, USA, 1-13.

[21] Jane Waite. 2017. Pedagogy in teaching Computer Science in schools : A Literature Review. Technical Report. Queen Mary University of London and King's College London, London.

[22] Jeannette M Wing. 2006. Computational thinking. Commun. ACM 49, 3 (2006), 33-35. 